\title{
İlkokul Öğretmenlerinin Eğitimde Teknoloji Kullanımına İlişkin Bilgisayar Yeterliliklerinin Değerlendirilmesi ${ }^{1}$
}

DOI: 10.26466/opus.779338

\author{
Muhammet Y1lmaz - Lütfi Üredi \\ *Öğretmen, MEB, Vakıfbank Ortaokulu, Adana \\ E-Posta: yilmazm01@gmail.com \\ ORCID: 0000-0001-7412-6368 \\ ${ }^{* *}$ Doç.Dr., Mersin Üniversitesi, Eğitim Fakültesi, İlköğretim Bölümü Sınıf Öğretmenliği \\ Anabilim Dalı, Mersin. \\ E-Posta: lutfiuredi@gmail.com \\ ORCID: $\underline{0000-0003-1705-1325}$
}

\section{Öz}

Bu çalışma, ilkokul öğretmenlerinin eğitimde teknoloji kullanımına ilişkin bilgisayar yeterliliklerinin (yaş, cinsiyet, öğrenim durumu, mesleki kıdem, okutulan sınıf ve simıfinda bilgisayar bulunma değişkenlerine göre) değerlendirilmesi amacıyla yapılmıştır. Araştırmanın evrenini Adana il merkezinde görev yapan ilkokul öğretmenlerinin tamamı, örneklemini ise Adana İl Milli Eğitim Müdürlüğü'ne bağ $l$ resmi ilkokullarda görev yapan 360 ilkokul öğretmeni oluşturmaktadır. Bu çalışma tarama modelinin kullanıldığı betimsel bir çalışmadır. Bu çalışmada ilkokul öğretmenlerinin, bilgisayar yeterliliklerini ortaya koymak amacıyla, "Algılanan Bilgisayar Yeterlilik Ölçeği" kullanılmıştır.Verilerin analizinde betimsel istatistiksel analizler gerçekleştirilerek, veriler yüzde, frekans, ortalama ve standart sapma şeklinde belirlenmiştir. Oluşturulan gruplar arasında puan bakımından anlamlı bir fark olup olmadığını test etmek için, bağımsız gruplar t-testi ve grup sayısına bağh olarak tek yönlü varyans analizi kullanılmıştır.Araştırma sonucuna göre, öğretmenlerin bilgisayar ile ilgili temel kavramları, kelime işlemci programların, Internet - World Wide Web kullanımı ve e-posta kullanımını iyi bildikleri, bilgisayarın fiziksel parçaları, işletim sistemi, hesaplama tablosu ve sunum programların orta düzeyde bildikleri tespit edilmiştir. Veritabanı programları ve Web sayfası geliştirme konularında ise yetersiz oldukları görülmüştür. Öğretmenlerin öğrenim durumuna göre bilgisayar yeterlilik puanlarn incelendiğinde ön lisans ve doktora mezunları arasında doktora yapan öğretmenler lehine anlamlı bir farklılık tespit edilmiştir.

Anahtar Kelimeler: İlkokul, İlkokul Öğretmeni, Teknoloji Kullanımı, Bilgisayar Destekli Eğitim, Teknoloji Tutumları

\footnotetext{
${ }^{1}$ Bu makale, Doç. Dr. Lütfi Üredi danışmanlığında; Mersin Üniversitesi Eğitim Bilimleri Enstitüsünde Sınıf Öğretmenliği programında gerçekleştirdiğim yüksek lisans tez çalışmasından üretilmiştir. Ayrıca, çalışmanın bir kısmı 24-26 Nisan 2017 tarihlerinde USEAS 2017 kongresinde sözlü bildiri olarak sunulmuştur ve bildiri özetleri kitapçığında basılmıştır.
} 


\title{
The Evaluation Of Primary School Teachers' Computer Competency Concerning The Use Of Technology In Education
}

\begin{abstract}
The aim of this study was to examine the primary school teachers' computer competency concerning the use of technology in education according to the variables: age, gender, educational background, professional seniority, class and the availability of computer in class. All the primary school teachers who work in the center of Adana province composed the universe of the study, and 360 primary school teachers who work in the official primary schools affiliated with Adana Provincial Education Directorate composed the sample of the study. This is a descriptive study in which survey model was used. "Perceived Computer Competency Scale" was used to reveal primary school teachers' computer competency. According to the result of the study, it was identified that teachers know the basic concepts about computer, word processor programs, use of the Internet - World Wide Web and use of e-mail well; they know the physical parts of the computer, operating system, calculation table programs and presentation programs at a moderate level. However, it was seen that they are insufficient at database programs and developing a website. When teachers' computer competency points were analyzed according to their educational background, it was identified that there was a significant difference between the associate degree and PHD graduates on behalf of the PHD.
\end{abstract}

Keywords: Primary School, Primary School Teacher, Use of Technology, Computer Aided Education, Technology Attitudes 


\section{Giriş}

Eğitim-öğretim çalışmalarının başarıya ulaşmasında eğitimin kalitesini belirleyici unsurlardan ve eğitim sisteminin ögelerinden biri olan öğretmenlerinin yeterlilikleri ve eğitimde teknoloji kullanımları oldukça önemlidir. "Yapılandırmacı yaklaşımın hâkim olduğu eğitim sistemimizde öğretmen, öğrenme öğretme süreçlerinde bilgi aktarmaktan ziyade, öğrencilere öğrenmelerinde rehberlik edici, yol gösterici bir konumda bulunmaktadır. Bilişim Teknolojileri, öğretmenlerin bu rehberliğinde en önemli yardımcısıdır. Bu nedenle bilişim teknolojilerin eğitim sürecinde etkin kullanılması, eğitim-öğretim etkinliklerinin daha verimli hale getirilmesi açısından çok önemlidir" (Yılmaz, Üredi ve Akbaşlı, 2014). Bilişim teknolojilerinin çok etkin kullanıldığı eğitim sistemimizde, öğretmenlerin sahip olması gereken özel alan yeterliliklerinden birisi de bilimsel ve teknolojik gelişimdir.

İlkokul kurumları eğitim sisteminin temel konumunda olması ile birlikte öğrencilerin hem bireysel hem de toplumsal yaşamında başarılı olmalarını sağlayacak özelliklerin kazandırılmasında anahtar rol oynamaktadır (Akyürek ve Şahin, 2013). Bireylerin gelecek yaşantıları için oldukça önemli olan ilkokullarda görev yapan öğretmenlerin özel alan yeterliliklerini, eğitimde teknoloji kullanımları da yakından etkileyebilecektir. Eğitimde teknoloji kullanımı ile öğrenme-öğretme ortamları etkilenebilecek, öğrencileri izleme ve değerlendirme çalışmaları kolaylaşacak, öğretmenlerin bireysel ve mesleki gelişimlerine katkı sağlanabilecek ve bilimsel ve teknolojik gelişimler yakından izlenebilecektir.

Teknolojinin gelişmesi, eğitim sisteminin yapısını ve eğitim ortamlarında uygulanan öğrenme-öğretme faaliyetlerini etkilemektedir. Öğretmenlerin öğretim metotlarını değiştirerek, eğitim teknolojilerini etkili bir şekilde kullanabilmeleri için zaman, güven, motivasyon ve eğitim destekli ortam gerekmektedir (Pala, 2006). Okullarda öğretme öğrenme ortamını etkili hale getirmenin yolu, öğrencilerin uyarıcı zenginliği ile derse katılmalarını sağlamaktır. Bu noktada bilgisayarın eğitim ortamında kullanılması uyarıcı zenginliği sağlayan bir unsur olmasını sağlamaktadır (Arslan, 2006).

Öğretmenlerin yaptığı eğitim-öğretim faaliyetleri ile eğitim sürecinde teknoloji kullanımı ve eğitim ortamı, eğitim-öğretimin niteliğini etkileyecektir. 
Öğretmenlerin teknolojiyi, bilgiye ulaşmada araç olarak kullanmasının eğitimde verimliliği artıracağı düşünülmektedir. Bu durum, temel eğitim basamağında daha da önemlidir.

Eğitim ve teknoloji insan yaşamının daha etkili duruma getirilmesinde önemli rolü olan iki temel öğedir. Her iki öğe de insanın doğal ve sosyal çevresine hâkim olma yönünde gösterdiği çabalarda başvurduğu iki temel araç olmuştur. Eğitim, insanın doğuştan kazandığı gizil güçlerin ve yeteneklerin açığa çıkarılmasına, onun daha güçlü, daha olgun, yaratıcı ve yapıcı bir varlık olarak gelişme ve büyümesine hizmet etmiştir. Teknoloji ise, insanoğlunun eğitim yoluyla kazandığı bilgi ve becerilerden daha etkin, daha verimli biçimde yararlanabilmesinde, onları daha sistemli ve bilinçli olarak uygulayabilmesinde yardımci olmuştur (Alkan, 2005).

Aslantaş (2014)'a göre eğitim ve öğretimde teknoloji kullanma nedenleri şunlardır:

- Eğitim ve öğretime erişimi arttırmak,

- Öğrenimin kalitesini yükseltmek,

- Eğitim maliyetlerini azaltmak,

- Eğitimde maliyet etkinliğini sağlamak,

- Teknolojik değişim zorunluluğuna karşıllk vermek,

- Öğrencilere çalışma ve özel hayatlarında ihtiyaç duyacakları becerileri teknoloji ile sağlamak.

Bilgisayar yeterliliği, bilgisayar okuryazarlığı olarak da adlandırılabilmektedir. Bilgisayar okuryazarlığı, kişisel bilgisayarları fazla zorlanmadan kullanabilme, bilgisayarlarda temel bazı işlemleri (kelime işlemcilerle yazı yazma, basit analizler, raporlar yapma, basit çizim programları kullanma, yazıcı kullanma vb.) gerçekleştirebilme yeterliliğidir (Çelik, Kocaman ve Önal, 2008). Bilgisayar yeterliliği, bireyin bilgisayar başında bir görevi gerçekleştirmek için bilgisayar kullanım yeteneği üzerine kabul ettiği algısıdır (Gürcan, 2005).

Sınıf öğretmenlerinin birden fazla dersten sorumlu olmaları nedeniyle çoklu disiplin ve disiplinler arası anlayışa dayalı yeterliklere sahip olmaları gerekmektedir (Bilgin, Tatar ve Ay, 2012). Öğrencileri kazanımlara ulaştırma için gerekli öğretim yöntem, teknik ve stratejilerinin kullanımında öğretmen merkezli ve geleneksel olanları tercih etme eğilimi gösteren öğretmenlerin, aynı yaklaşımı bilgisayar ve ona bağlı materyallerin kullanımında da göste- 
rebilme ihtimali olabilmektedir. Öğretmenlerin bunun ötesine geçip, “bilgisayar destekli eğitim" ile "bilgisayar temelli eğitim"i ayırabilen, bilgisayarı sadece projeksiyondan sunu yapma amacının ötesine taşıyabilen, simülasyonlar, programlı öğretim modülleri, e-öğrenme uygulamaları, interaktif çalışmalar vb. yapabilecek pedagojik formasyona sahip olmaları gerekir. Bu formasyona sahip olan öğretmenlerin, teknolojiye ve teknolojinin öğrenme ortamlarında kullanımına yönelik olumsuz tutum, algı ve önyargıya sahip olma ihtimallerinin düşmesi beklenir (Berkant, 2013). Öğrencilerin bilgisayarı bir öğrenme aracı olarak görmesinde, bilgisayara yönelik tutumları etkilidir ve bu tutum, bilgisayarın gelecekte öğrenme ve çalışma ortamlarında tercih edilip kullanılmasında önemli bir rol oynamaktadır (Teo, 2008).

\section{Araştırma Problemi}

Bu araştırmanın problem cümlesi "Illkokul öğretmenlerinin eğitimde teknoloji kullanımına ilişkin bilgisayar yeterlilikleri hangi düzeydedir?" şeklinde oluşturulmuştur.

\section{Alt Problemler}

$\mathrm{Bu}$ araştırmada aşağıdaki araştırma problemlerine cevap aranmaya çalışılmıştır:

İlkokul öğretmenlerinin eğitimde teknoloji kullanımına ilişkin bilgisayar yeterlilikleri:

1. Yaşına göre farklılaşmakta mıdır?

2. Cinsiyetine göre farklılaşmakta mıdır?

3. Eğitim durumuna göre farklılaşmakta mıdır?

4. Mesleki kıdemine göre farklılaşmakta mıdır?

5. Okuttuğu sınıfa göre farklılaşmakta mıdır?

6. Sınıflarında bilgisayar olma durumuna göre farklılaşmakta mıdır?

\section{Yöntem}

Bu bölümde araştırmanın modeli, çalışma grubu, izlenen yöntem, veri toplama aracı, veri toplama aracının uygulanması, elde edilen verilerin analiz yöntemleri, geçerlik ve güvenirlik üzerinde durulmuştur. 


\section{Araştırmanın Modeli}

Araştırma tarama modelinin kullanıldığı betimsel bir çalışmadır. Çünkü tarama modelleri geçmişte ya da halen var olan bir durumu var olduğu şekli ile betimlemeyi amaç edinen araştırmalar için uygun bir modeldir (Karasar, 2006). Sosyal bilimlerde yaygın olarak kullanılan tarama araştırmaları, geniş gruplar üzerinde yürütülen, gruptaki bireylerin bir olgu ve olayla ilgili olarak görüşlerinin, tutumlarının alındığı, olgu ve olayların betimlenmeye çalışıldığı araştırmalardır. Araştırmacı burada var olan durumu ayrıntısıyla betimlemeye ve durum hakkında bilgi vermeye çalışır (Karakaya, 2009). Bu yöntem içerisinde hem sosyal bilimlerde hem de eğitimde en çok yararlanılan veri toplama araçlarından biri olan ölçek uygulaması yapılmıştır. Çalışma, ilkokul öğretmenlerinin eğitimde teknoloji kullanımına ilişkin bilgisayar yeterliliklerinin yaş, cinsiyet, öğrenim durumu, mesleki kıdem, okutulan sınıf ve sınıfında bilgisayar bulunma değişkenlerine göre belirlenmesi yönüyle betimsel bir çalışmadır.

\section{Araştırmanın Çalışma Grubu}

Araştırmanın evrenini Adana il merkezinde görev yapan tüm ilkokul öğretmenleri, örneklemini ise Adana İl Milli Eğitim Müdürlüğü'ne bağlı resmi ilkokullarda görev yapan toplamda 360 ilkokul öğretmeni oluşturmaktadır.

Araştırmaya katılan sınıf öğretmenlerine ilişkin demografik veriler 1'de yer almaktadır.

Araştırma 360 sınıf öğretmeni ile yürütülmüş olup araştırmaya katılan ilkokul öğretmenlerinden 61'i (\% 16.9) 20-29 yaş aralığında, 87'si (\% 24.2) 3029 yaş aralığında, 136'sı (\% 37.8) 40-49 yaş aralığında, 76'sı (\% 21.1) 50 yaş ve üzerinde bulunmaktadır. Katılan öğretmenlerden 159'u (\%44.2) erkek, 201'i (\% 55.8) kadındır. Öğretmenlerin öğrenim durumları incelendiğinde 73'ü (20.3) ön lisans, 262'si (72.8) lisans, 22'si (6.1) yüksek lisans, 3'ü (0.8) doktora mezunudur. Araştırmaya katılan öğretmenlerin mesleki kıdemi; 0-4 yıl olanlar \% 3.9 ile 14 kişi, 5-9 yıl olanlar \%15.8 ile 57 kişi, 10-14 yıl olanlar \% 19.7 ile 71 kişi, 15-19 yıl olanlar \%21.9 ile 79 kişi ve 20 yıl ve üzeri olan \%38.6 ile 139 kişiden oluşmaktadır. Öğretmenlerin 88'i (\%24.4) 1. sınıfı, 93'ü (\%25.8) 2. s1nıfı, 107'si (\%29.7) 3. sınıfı ve 72'si (\%20.0) 4. sinıfı okutmaktadır. Bu öğretmenlerin 264'ünün (\%73.3) sınıfında bilgisayar bulunmakta, 96'sının (\%26.7) bulunmamaktadır. 
Tablo 1. Sını Öğretmenlerine İlişkin Demografik Veriler

\begin{tabular}{|c|c|c|c|}
\hline Kişisel Bilgiler & & $\mathrm{f}$ & $\%$ \\
\hline \multirow{4}{*}{ Yaş } & $20-29$ & 61 & 16,9 \\
\hline & $30-39$ & 87 & 24,2 \\
\hline & $40-49$ & 136 & 37,8 \\
\hline & 50 ve üzeri & 76 & 21,1 \\
\hline \multirow[t]{2}{*}{ Cinsiyet } & Erkek & 159 & 44,2 \\
\hline & Kadın & 201 & 55,8 \\
\hline \multirow[t]{4}{*}{ Öğrenim Durumu } & Önlisans & 73 & 20,3 \\
\hline & Lisans & 262 & 72,8 \\
\hline & Yüksek Lisans & 22 & 6,1 \\
\hline & Doktora & 3 & 0,8 \\
\hline \multirow[t]{5}{*}{ Mesleki Kıdem } & $0-4$ Yll & 14 & 3,9 \\
\hline & 5-9 Yll & 57 & 15,8 \\
\hline & 10-14 yll & 71 & 19,7 \\
\hline & 15-19 Yil & 79 & 21,9 \\
\hline & 20 ve üzeri & 139 & 38,6 \\
\hline \multirow[t]{4}{*}{ Okutulan Sinıf } & 1.Sinif & 88 & 24,4 \\
\hline & 2.Sinif & 93 & 25,8 \\
\hline & 3.Sinif & 107 & 29,7 \\
\hline & 4.Sinif & 72 & 20,0 \\
\hline $\begin{array}{ll}\text { Sinifta } & \text { Bilgisayar }\end{array}$ & Evet & 264 & 73,3 \\
\hline Olma Durumu & Hayır & 96 & 26,7 \\
\hline
\end{tabular}

\section{Veri Toplama Araçları}

Bu araştırmada veri toplama aracı 2 bölümden oluşmaktadır. Birinci bölüm, araştırmacı tarafından yapılandırılmış olan kişisel bilgilere yönelik sorularla demografik veriler elde etmek amaciyla demografik bilgi formu kullanılmıştır. Bu bölümde öğretmenlere, yaş, cinsiyet, mesleki kıdem, öğrenim durumu, okutulan sınıf düzeyi ve sınıfta bilgisayar bulunma durumu gibi demografik bilgiler ve özellikler sorulmuştur.

İkinci bölümde, ilkokul öğretmenlerinin bilgisayar yeterliliklerini ortaya koymak amacıyla Tınmaz (2004) tarafından geliştirilen 10 maddeden oluşan likert tipi 3 dereceli zayıf, orta ve iyi şeklinde düzenlenmiş olan Ölçeğin Cronbach Alpha katsayısı 0,87 olarak hesaplanmış olan "Algılanan Bilgisayar Yeterlilik Ölçeği” (A.B.Y.Ö.) yer almaktadır. Ölçekte bilgisayarla ilgili temel kavramlar, donanım, işletim sistemi, word, excel, powerpoint, access programları ile web sayfası geliştirme ve internet kullanımına ilişkin sorular yer almaktadır. Algılanan Bilgisayar Yeterlilik Ölçeğinde yer alan her madde "iyi" (3), "orta" (2), "zayıf" (1) şeklinde değerlendirilmektedir. Buna göre, elde edilen veriler 3'den 1'e kadar bir değer verilerek kodlanmaktadır. 


\section{Verilerin Toplanmast}

Araştırmada öncelikle Adana İl Milli Eğitim Müdürlüğü yetkilileriyle görüşülerek Adana il merkezindeki Yüreğir, Seyhan, Çukurova ve Sarıçam ilçelerindeki ilkokulların listesi elde edilmiştir. Daha sonra tesadüfi örnekleme yöntemiyle rasgele okullar seçilmiş ve gerekli resmi izinler alınmıştır. Seçilen okullarda ölçeği doldurmak isteyen öğretmenlere öncelikle araştırma hakkında bilgi verilerek bireysel olarak dağıtılmış ve bireysel olarak ölçekleri doldurmaları istenmiştir. Ölçek doldurulduktan hemen sonra araştırmacı tarafından toplanmışır. Demografik bilgi formu ve ölçeklerin uygulanması esnasında tarafsız ve objektif bir ortam sağlanmasına azami önem verilmiştir. Demografik bilgi formu ve ölçeklerin doldurulması yaklaşık 10-15 dk. aralığında sürmüştür.

\section{Verilerin Analizi}

Kişisel bilgi formu ile elde edilen nicel veriler, frekans ve yüzdeleri alınarak değerlendirilmiştir. Algılanan Bilgisayar Yeterlilik Ölçeğinden elde edilen veriler SPSS 20 programına girilerek analiz edilmiştir. Analiz doğrultusunda elde edilen nicel verilerin frekans dağılımı ve yüzdeleri alınarak sunulmuştur. Verilerin analizinde betimsel istatistiksel analizler gerçekleştirilerek, veriler yüzde, frekans, ortalama ve standart sapma şeklinde belirlenmiştir. Oluşturulan gruplar arasında puan bakımından anlamlı bir fark olup olmadığını test etmek için, bağımsız gruplar t-testi ve grup sayısına bağlı olarak tek yönlü varyans analizi kullanılmıştır. Gruplar arasında gözlenen anlamlı farkın hangi gruplar arasında olduğunu belirlemek için ise Tukey HSD testi kullanılmıştır.

\section{Bulgular ve Yorumlar}

Bu bölümde ölçeğin uygulanmasından elde edilen nicel verilerin istatistiksel analizleri ile ortaya çıkn bulgular ve bunlara ilişkin yorumlar yer almaktadır. Öğretmenlerin bilgisayar yeterlilik puanları yaş, cinsiyet, öğrenim durumu, mesleki kıdem, okutulan sinıf ve sınıfında bilgisayar bulunma gibi bağımsız değişkenler açısından değerlendirilmiştir.

Birinci alt probleme (İlkokul öğretmenlerinin eğitimde teknoloji kullanımlarına ilişkin bilgisayar yeterlilikleri hangi düzeydedir) ilişkin bulgular: 
Öğretmenlerin bilgisayar yeterlilik puanları ortalaması Tablo 2'de sunulmuştur.

Tablo 2. Öğretmenlerin Bilgisayar Yeterlilik Puanlarnna İlişkin Frekans, Yüzde ve Aritmetik Ortalama Değerleri

\begin{tabular}{|c|c|c|c|c|c|c|c|}
\hline \multirow{2}{*}{ Kavram } & \multicolumn{2}{|c|}{ Zayif } & \multicolumn{2}{|c|}{ Orta } & \multicolumn{2}{|l|}{ İyi } & \multirow[t]{2}{*}{$\bar{X}$} \\
\hline & $\mathbf{n}$ & $\%$ & $\mathbf{n}$ & $\%$ & $\mathbf{n}$ & $\%$ & \\
\hline a. Bilgisayarla ilgili temel kavramlar & 23 & 6,4 & 152 & 42,2 & 185 & 51,4 & 2,45 \\
\hline b. Bilgisayarın fiziksel parçaları (donanım) & 91 & 25,3 & 173 & 48,1 & 96 & 26,7 & 2,01 \\
\hline c. İşletim Sistemi (Ör: Windows) & 58 & 16,1 & 162 & 45,0 & 140 & 38,9 & 2,23 \\
\hline d. Kelime İşlemci Programlar (Ör: Word) & 44 & 12,2 & 155 & 43,1 & 161 & 44,7 & 2,33 \\
\hline e. Hesaplama Tablosu Programları (Ör: Excel) & 126 & 35,0 & 171 & 47,5 & 63 & 17,5 & 1,83 \\
\hline f. Sunum Programları (Ör: Powerpoint) & 74 & 20,6 & 159 & 44,2 & 127 & 35,3 & 2,15 \\
\hline g. Veritabanı Programları (Ör: Access) & 173 & 48,1 & 148 & 41,1 & 39 & 10,8 & 1,63 \\
\hline h. Web Sayfası geliştirme (Ör: Frontpage, Dreamweaver) & 218 & 60,6 & 123 & 34,2 & 19 & 5,3 & 1,45 \\
\hline i.Internet - World Wide Web (www) kullanımı & 60 & 16,7 & 132 & 36,7 & 168 & 46,7 & 2,30 \\
\hline j. E-posta (E-mail) kullanımı & 49 & 13,6 & 117 & 32,5 & 194 & 53,9 & 2,40 \\
\hline
\end{tabular}

Tablo 2 incelendiğinde, öğretmenlerin bilgisayarla ilgili temel kavramları, kelime işlemci programları, Internet- World Wide Web kullanımı ve e-posta kullanımını iyi bildikleri, bilgisayarın fiziksel parçaları, işletim sistemi, hesaplama tablosu programları ve sunum programlarını orta düzeyde bildikleri görülmektedir. Veritabanı programları ve Web sayfası geliştirme konularında ise yetersiz oldukları görülmektedir. Öğretmenlerin iyi olduğu yönler genellikle sıklıkla bilgisayar teknolojilerinin kullanıldığı alanlardır. Bu durum öğretmenlerin günümüz teknolojilerinden yararlandıklarını gösterebilir.

İkinci alt probleme (ìlkokul öğretmenlerinin eğitimde teknoloji kullanımına ilişkin bilgisayar yeterlilikleri öğretmenlerin yaş, cinsiyet, eğitim durumu, mesleki kıdem, okuttuğu sinıfve sinfflarnda bilgisayar olma durumuna göre farklılaşmakta mıdır?) ilişkin bulgular:

Öğretmenlerin yaşına göre bilgisayar yeterlilik puanlarının tek yönlü varyans analizi sonuçları Tablo 3'te sunulmuştur.

Tablo 3. Öğretmenlerin Yaşına Göre Bilgisayar Yeterlilik Puanlarnnın Tek Yönlü Varyans Analizi Sonuçları

\begin{tabular}{llllll}
\hline Varyans Kaynağı & Kareler Toplamı & Sd & Kareler Ortalaması & F & p \\
\hline Gruplar Arası & 267,109 & 3 & 89,036 & 4,685 & $0,03^{*}$ \\
Gruplar İçi & 6765,291 & 356 & 19,004 & & \\
Toplam & 7032,400 & 359 & & & \\
\hline
\end{tabular}


Tablo Tablo 3 incelendiğinde, tek yönlü varyans analizi sonuçlarına göre, öğretmenlerin yaşına göre bilgisayar yeterlilik puanları açısından genel olarak gruplar arasındaki farkın istatistiksel olarak anlamlı olduğu görülmekte$\operatorname{dir}[\mathrm{F}(3,356)=4,685 \mathrm{p}<0,05]$.

Gruplar arasında gözlenen anlamlı farkın hangi gruplar arasında olduğuna bakmak için Tukey HSD testi yapılmış ve buna ilişkin sonuçlar Tablo 4'te sunulmuştur.

Tablo 4. Öğretmenlerin Yaşına Göre Bilgisayar Yeterlilik Puanlarının Tukey HSD Testi Sonuçları

\begin{tabular}{llll}
\hline \multirow{2}{*}{ Gruplar } & Ortalama Fark & $\begin{array}{l}\text { Standart } \\
\text { Hata }\end{array}$ & $\mathbf{p}$ \\
\hline (20-29 Yaş) - (30-39 Yaş) & 2,138685 & 0,727989 & 0,18 \\
(20-29 Yaş) - (40-49 Yaş) & 1,827748 & 0,671764 & 0,34 \\
(20-29 Yaş) - (50 ve üzeri Yaş) & 2,685720 & 0,749388 & $0,02^{*}$ \\
(30-39 Yaş) - (40-49 Yaş) & 0,310936 & 0,598469 & 0,95 \\
(30-39 Yaş) - (50 ve Üzeri Yaş) & 0,547036 & 0,684456 & 0,85 \\
(40-49 Yaş) - (50 ve Üzeri Yaş) & 0,857972 & 0,857972 & 0,51 \\
\hline
\end{tabular}

Öğretmenlerin bilgisayar yeterlilik puanlarının yaşlarına göre hangi gruplar arasında anlamlı farklılık olup olmadığını ortaya koymak amacıyla Tablo 4 incelendiğinde, 20-29 yaş ile 50 yaş ve üzeri olanlar arasında 20-29 yaş aralığındaki öğretmenler lehine anlamlı farklılık elde edilmiştir. Sınıf öğretmenlerinin yaş ilerledikçe bilgisayar kullanım durumlarının azaldığı ifade edilebilir.

Öğretmenlerin cinsiyetine göre bilgisayar yeterlilik puanlarına ilişkin bağımsız gruplar $\mathrm{t}$ testi sonuçları Tablo $5^{\prime}$ te sunulmuştur.

Tablo 5. Cinsiyetine Göre Bilgisayar Yeterlilik Puanlarnna İlişkin Bağımsız Gruplar TTesti Sonuçları

\begin{tabular}{lllllll}
\hline Cinsiyet & $\mathbf{N}$ & $\overline{\boldsymbol{X}}$ & $\mathbf{S}$ & $\mathbf{S d}$ & $\mathbf{t}$ & $\mathbf{p}$ \\
\hline Erkek & 159 & 20,64 & 4,18 & 358 & $-0,45$ & 0,65 \\
Kadın & 201 & 21,86 & 4,61 & 351 & & \\
\hline
\end{tabular}

Tablo 5'te görüldüğü üzere, öğretmenlerin cinsiyetine göre bilgisayar yeterlilik puanları açısından $t$ testi sonuçları incelendiğinde anlamlı farklılık görülmemektedir. Bu bilgisayara her iki cinsiyetinde aynı oranda ulaşabilmesiyle ilişkili olabilir. Bu bulguya göre bilgisayar yeterlik puanlarının cinsiyete göre değişmediği söylenebilir. 
Sınıf öğretmenlerinin öğrenim durumuna göre bilgisayar yeterlilik puanlarına ilişkin varyans analizi sonuçları Tablo 6'da sunulmuştur.

Tablo 6. Öğretmenlerin Öğrenim Durumuna Göre Bilgisayar Yeterlilik Puanlarnın Tek Yönlü Varyans Analizi Sonuçlan

\begin{tabular}{llllll}
\hline Varyans Kaynağı & Kareler Toplamı & Sd & Kareler Ortalaması & F & p \\
\hline Gruplar Arası & 216,756 & 3 & 72,252 & 3,773 & $0,01^{*}$ \\
Gruplar İçi & 6815,644 & 356 & 19,145 & & \\
Toplam & 7032,400 & 359 & & & \\
\hline
\end{tabular}

Tablo 6 incelendiğinde, tek yönlü varyans analizi sonuçlarına göre, öğretmenlerin öğrenim durumuna göre bilgisayar yeterlilik puanları açısından genel olarak gruplar arasındaki farkın istatistiksel olarak anlamlı olduğu görülmektedir $[F(3,356)=3,773 p<0,05]$. Bilgisayar yetelilik puanlarının öğrenim düzeyi ile doğrudan bağlantılı olduğu düşünülmektedir.

Gruplar arasında gözlenen anlamlı farkın hangi gruplar arasında olduğuna bakmak için Tukey HSD testi yapılmış ve buna ilişkin sonuçlar Tablo 7'de sunulmuştur.

Tablo 7. Öğretmenlerin Öğrenim Durumuna Göre Bilgisayar Kullanım Puanlarnnn Tukey HSD Testi Sonuçları

\begin{tabular}{llll}
\hline Gruplar & Ortalama Fark & Standart Hata & p \\
\hline (Önlisans) - (Lisans) & 0,978929 & 0,579080 & 0,33 \\
(Önlisans) - (Yüksek Lisans) & 2,423412 & 1,064186 & 0,10 \\
(Önlisans) - (Doktora) & 6,817352 & 2,577586 & $0,04^{*}$ \\
(Lisans) - (Yüksek Lisans) & 1,444483 & 0,971238 & 0,44 \\
(Lisans) - (Doktora) & 5,838422 & 2,540622 & 0,10 \\
(Yüksek Lisans) - (Doktora) & 4,393939 & 2,692939 & 0,36 \\
\hline
\end{tabular}

Öğretmenlerin bilgisayar yeterlilik puanlarının öğrenim durumuna göre hangi gruplar arasında anlamlı farklılık olup olmadığını ortaya koymak amacıyla Tablo 7 incelendiğinde, önlisans ve doktora mezunları arasında anlamlı bir farklılık görülmektedir. Bu durum doktora mezunlarının tez hazırlama ve literatür araştırma sürecinde daha çok bilgisayar kullanımıyla karşılaşması ve bilgiye erişim için bilgisayar teknolojilerini kullanmak durumunda kalmaları nedeniyle ortaya çımış olabilir.

Sınıf öğretmenlerinin mesleki kıdemlerine göre bilgisayar yeterlilik puanlarına ilişkin varyans analizi sonuçları Tablo 8'de sunulmuştur. 
Tablo 8. Öğretmenlerin Mesleki Kıdemine Göre Bilgisayar Yeterlilik Puanlarının Tek Yönlü Varyans Analizi Sonuçlarn

\begin{tabular}{llllll}
\hline Varyans Kaynağı & Kareler Toplamı & Sd & $\begin{array}{l}\text { Kareler Orta- } \\
\text { laması }\end{array}$ & F & p \\
\hline Gruplar Arası & 107,686 & 4 & 26,921 & 1,380 & 0,24 \\
Gruplar İçi & 6924,713 & 355 & 19,506 & & \\
Toplam & 7032,400 & 359 & & & \\
\hline
\end{tabular}

Tablo 8 incelendiğinde, tek yönlü varyans analizi sonuçlarına göre, öğretmenlerin mesleki kıdemine göre bilgisayar yeterlilik puanları açısından genel olarak gruplar arasındaki farkın istatistiksel olarak anlamlı olmadığı görülmektedir $[F(4,355)=1,380$ p>0,05]. Son yıllarda Milli Eğitim Bakanlı̆̆ı öğretmenlerin bilgisayar kullanımını teşvik etmiş ve bilgisayar üzerinden veri girişini zorunlu hale getirmiştir. Ayrıca teknolojik ilerlemelerle bilgisayarla karşlaşmamak neredeyse imkansız hale gelmiştir. Bu durumların her kademedeki öğretmenlerin bilgisayar yeterliliklerini geliştirdiği düşünülmektedir.

Okutulan sınıfa göre bilgisayar yeterlilik puanlarına ilişkin varyans analizi sonuçları Tablo 9'da sunulmuştur.

Tablo 9. Öğretmenlerin Okutulan Sinıfa Göre Bilgisayar Yeterlilik Puanlarının Tek Yönlï Varyans Analizi Sonuçlan

\begin{tabular}{llllll}
\hline Varyans Kaynağı & $\begin{array}{l}\text { Kareler } \\
\text { Toplamı }\end{array}$ & Sd & Kareler Ortalaması & F & p \\
\hline Gruplar Arası & 17,324 & 3 & 5,774 & 0,293 & 0,83 \\
Gruplar İçi & 7015,075 & 356 & 19,705 & & \\
Toplam & 7032,400 & 359 & & & \\
\hline
\end{tabular}

Tablo 9 incelendiğinde, tek yönlü varyans analizi sonuçlarına göre, öğretmenlerin okutulan sınıfa göre bilgisayar yeterlilik puanları açısından genel olarak gruplar arasındaki farkın istatistiksel olarak anlamlı olmadığı görülmektedir $[F(3,356)=0,293 p>0,05]$. Bu sonuç, öğretmenlerin hangi sınıfı okuttuğuna bakılmaksızın bilgisayar kullanmak durumunda olmaları ve bilgisayarın eğitimde kullanımın öneminin farkında olmaları ile değerlendirilebilir. Bunun yanı sıra ilkokulun her sınıf düzeyine uygun bilgisayar destekli öğretim materyallerinin bulunması da bu duruma olumlu katkı sunmuş olabilir.

Öğretmenlerin sınıfta bilgisayar olma durumuna göre bilgisayar yeterlilik puanlarına ilişkin bağımsız gruplar t testi sonuçları Tablo 10`da sunulmuştur. 
Tablo 10. Sınfta bilgisayar olma durumuna göre bilgisayar yeterlilik puanlarna ilişkin bağımsız gruplar t-testi sonuçları

\begin{tabular}{lllllll}
\hline Sinifta Bilgisayar Var mı? & $\mathbf{N}$ & $\overline{\boldsymbol{X}}$ & $\mathbf{S}$ & $\mathbf{S d}$ & $\mathbf{t}$ & $\mathbf{p}$ \\
\hline Evet & 264 & 21,04 & 4,44 & 358 & 1,96 & $0,04^{*}$ \\
Hayır & 96 & 20,01 & 4,30 & 173 & & \\
\hline
\end{tabular}

Tablo 10'da görüldüğü üzere, sinıfta bilgisayar olma durumuna göre bilgisayar yeterlilik puanları açısından $t$ testi sonuçları incelendiğinde, sınıfında bilgisayar bulunan öğretmenlerle sınıfında bilgisayar bulunmayan öğretmenlerin bilgisayar yeterlilik puanları arasında sınıfinda bilgisayar bulunanlar lehine anlamlı farklılık elde edilmiştir $(t(173)=1,96, p<0.05)$. Bilgisayar kullanılarak zaman içerisinde daha çok bilgi ve beceri sahibi olunabilmektedir.

\section{Sonuç ve Tartışma}

Bu bölümde araştırmanın bulguları doğrultusunda elde edilen sonuçlar ortaya konmuş, öğretmenlerin eğitimde teknoloji kullanımı ve bilgisayar yeterliliklerinin artırılmasına yönelik öneriler geliştirilmiştir. Sonuçların sunumunda araştırmanın alt problemleri esas alınmış, her bir sonuç ile ilgili ayrıntılı sonuç verilmiştir. Bütün bulgu ve sonuçlara dayanarak uygulayıcılara ve araştırmacılara öneriler sunulmuştur.

Yapılan bu araştırma sonucunda, araştırmaya katılan öğretmenlerin bilgisayarla ilgili temel kavramları, kelime işlemci programları, Internet - World Wide Web kullanımı ve e-posta kullanımını iyi bildikleri, bilgisayarın fiziksel parçaları, işletim sistemi, hesaplama tablosu programları ve sunum programlarını orta düzeyde bildikleri görülmüştür. Veritabanı programları ve Web sayfası geliştirme konularında ise yetersiz oldukları görülmüştür. Gürbüztürk, Demir, Karadağ ve Demir (2015), sınıf öğretmenlerinin bilgisayar ve internet kullanımına ilişkin öz-yeterlik algılarını bazı değişkenler açısından incelemek amacıyla ilkokullarda görev yapan 165 sinıf öğretmeniyle bir araştırma yürütmüştür. Araştırma sonucunda, öğretmenlerin bilgisayar ve internet kullanımına ilişkin özyeterlik algılarının uzmanlık gerektiren bazı beceriler dışında, genel olarak yüksek olduğu, öğretmenlerin mesleki kıdemlerine ve mezun oldukları yükseköğretim kurumuna göre, bilgisayar ve internet kullanımı öz-yeterlik algıları arasında anlamlı bir farkın olduğu ortaya çıkmıştır. Gümüşdağ ve ark. (2013), beden eğitimi öğretmenlerinin bilgisayar 
kullanımındaki yeterliklerini ve tutumlarını sınıf içinde ve dışında nasıl kullandıklarını tespit etmeyi amaçlamak amacıyla yaptıkları araştırma sonucunda öğretmenlerin büyük çoğunluğu hesap tabloları (Excel), kelime işlemci (Word) ve sunu hazırlama (Powerpoint) konularında çok az bilgi sahibi oldukları tespit edilmiştir.

Öğretmenlerin yaşına göre bilgisayar yeterlilik puanları açısından genel olarak gruplar arasındaki farkın istatistiksel olarak anlamlı olduğu görülmüştür. 20-29 yaş ile 50 yaş ve üzeri olanlar arasında 20-29 yaş aralığındaki öğretmenler lehine anlamlı farklılık elde edilmiştir. Williams ve Kingham (2003), yaş ile tutarlı bir değişken olan deneyim üzerine yaptıkları bir araştırmada da tecrübeli öğretmenlerin sınıflarında teknoloji kullanmada çok fazla istekli olmadıkları görülmüştür.

Öğretmenlerin cinsiyetine göre bilgisayar yeterlilik puanları açısından sonuçlar incelendiğinde anlamlı farklılık görülmemiştir. Timur, Yılmaz ve Timur (2013), öğretmen adaylarının bilgisayar kullanımına yönelik öz-yeterlilik inançlarını değerlendirmek amacıyla yaptıkları çalışmada, bilgisayar kullanımına yönelik öz-yeterlik inancının cinsiyete göre değişmediği, bilgisayar kullanımına yönelik öz-yeterlik inancı ölçeğinin sonuç beklentisi alt boyutunda cinsiyete göre anlamlı fark bulunduğu tespit edilmiştir. Seferoğlu ve Akbıyık (2005), ilköğretim öğretmenlerinin bilgisayara yönelik öz-yeterlik algıları üzerine yaptıkları çalışmalarında, kadın ve erkek öğretmenler arasında bilgisayar öz-yeterlik algısı açısından anlamlı bir fark bulamamışlardır.

Öğretmenlerin öğrenim durumuna göre bilgisayar yeterlilik puanları açısından genel olarak gruplar arasındaki farkın istatistiksel olarak anlamlı olduğu görülmektedir. Sonuçlar incelendiğinde, önlisans ve doktora mezunları arasında doktora mezunları lehine anlamlı bir farklılık görülmüştür. Akgül, Küpeli ve Kır (2015), sınıf öğretmenlerinin bilgisayar okur-yazarlik düzeylerinin belirlenmesi amacıyla yaptıkları çalışmada, önlisans ve lisansüstü mezunları arasında lisansüstü mezunları lehine anlamlı bir farklılık bulmuşlardir.

Sınıfta bilgisayar olma durumuna göre bilgisayar yeterlilik puanları açısından sonuçlar incelendiğinde, sınıfında bilgisayar bulunan öğretmenlerle sınıfında bilgisayar bulunmayan öğretmenlerin bilgisayar yeterlilik puanları arasında sınıfında bilgisayar bulunanlar lehine anlamlı farklılık elde edilmiştir. 


\section{Öneriler}

Araştırmanın sonuçlarına göre, şu öneriler geliştirilmiştir:

1. Yerel Yönetim ya da Bakanlığa Öneriler:

- Öğretmenler özellikle sınıf öğretmenleri, sınıflarında bilgisayarları nasıl kullanacakları konusunda desteklenmeli ve öğretmenlere gerekli eğitim sağlanmalıdır.

- Her kademedeki okul, bilgisayar formatörleri aracıllğıyla desteklenmelidir.

- Öğretim programları bilgisayar kullanımı eşliğinde yürütülmelidir.

- Öğretmenlerin bilgisayar kullanımı konusunda hizmet içi eğitimlerle desteklenmelidir.

- Okullarda öğretmenler, öğrenciler ve ailelerin erişim sağlayabileceği elektronik kütüphanelere erişim alanları oluşturulmalıdır.

- Öğretmen adaylarının lisans eğitiminde Fatih Projesi kapsamında okullarda kullanılan etkileşimli tahtalarla ilgili gerekli bilgi donanımı sağlanabilir.

2. Araştırmacılara Öneriler:

- FATİH projesi ilkokullarda uygulanmaya başladıktan sonra çalışmanın tekrar ve daha kapsamlı bir şekilde araştırılması önerilmektedir.

- Bu araştırma, değişik sosyoekonomik düzeyde bulunan bölgelerdeki okullarda çalışan öğretmenlerle yürütülerek, sosyoekonomik düzeyin etkisi araştırılabilir.

- Eğitimde teknoloji kullanımına ilişkin tutumları yüksek düzeyde olan öğretmenlerin öğrencileri ile düşük düzeyde olan öğretmenlerin öğrencileri, akademik başarı açısından karşılaştırılabilir.

3. Öğretmenlere Öneriler:

- Eğitim-öğretim çalışmalarının daha etkili ve verimli olabilmesi için teknolojiyi etkin kullanmaları önerilmektedir.

Eğitim portallarından (eba.gov.tr vb.) faydalanmaları önerilmektedir. 


\title{
EXTENDED ABSTRACT
}

\section{The Evaluation Of Primary School Teachers' Computer Competency Concerning The Use Of Technology in Education}

\author{
Muhammet Yilmaz - Lütfi Üredi \\ Ministry of National Education, Mersin University
}

Teachers constitute for the most significant part in the success of educational activities. To improve the quality of education, teachers need to improve themselves in every aspect. One of the special field competencies of teachers prepared by the Ministry of National Education and becoming valid in 2008 is the scientific and technological development. In our education system, which is dominated by the constructivist approach, the teacher is in the position of supervising the students in their learning, rather than transferring them information in the learning and teaching process. Information technologies are the most important aids of teachers in this mentoring practice. In our country, technology in the institutions of secondary and higher education started to be used more, and teachers' technology use has become almost compulsory at all levels of education. The latest example of this is the FATIH (action to increase opportunities and technology improvement) project initiated by the Ministry of National Education in 2012. The most important objective of this project is to ensure that every teacher and student have the same opportunities to access to the resources and technological equipments. Primary education teachers' use of technology and their related attitudes have become more important in terms of the constitution of basic education as the first step of education levels and forming the background through the knowledge and skills learned at this level for the following education levels. Therefore, it is important to investigate classroom teachers' computer competencies and perspectives on the use of technology in education. This study was conducted to evaluate the computer proficiencies (age, gender, educational background, professional seniority, classroom and classroom availability) of primary school teachers in their classroom settings. As a result of this study, it is thought that the computer skills of primary school teachers will 
guide the Ministry of National Education which desires to include the FATİH project in primary school level. Through this study, the current state of primary school teachers regarding the use of education technologies, which is an indispensable part of the teaching process, can be determined and consequently this can contribute to the necessary precautions and improvement works on the use of educational technologies. The population of the study consists of all primary school teachers working in Adana city center and the sample is composed of 360 primary school teachers working in official primary schools affiliated by Adana Provincial Directorate of National Education. The study is a descriptive survey model. In this study, the data collection tool includes two parts. In the first part, a demographic information form was used to obtain demographic data through questions on personal information structured by the researcher. In this section, teachers were asked about such demographic information as age, gender, seniority, education level, class level and computer availability. In the second part, in order to determine the computer proficiency of primary school teachers, a Perceived Computer Adequacy Scale, which is composed of 10 items with 3 scales as weak, medium and good, was utilized. The Cronbach Alpha coefficient of the scale was found to be 0.87 . The quantitative data obtained through the personal information form were evaluated by counting frequencies and percentages. The data obtained from the perceived computer proficiency scale were analyzed through SPSS 20 program. The frequency distribution and percentages of the quantitative data obtained from the analysis are presented. The descriptive statistical analyses were performed in the analysis of the data and the data were determined as percentage, frequency, mean and standard deviation. In order to test whether there was a significant difference between the groups in terms of scores, independent groups t-test and one-way variance analysis depending on the number of groups were carried out. Tukey HSD test was used to determine the significant difference between the groups. According to the results of the research, it is seen that teachers are familiar with basic computer concepts, word processing programs, Internet-World Wide Web and e-mail usage. Teachers seem to be familiar with the physical parts of the computer, operating system, spreadsheet programs and presentation programs. It is seen that they are inadequate in database programs and Web page development. The points that teachers are good at are often the areas where computer technologies are commonly used. This may indicate that teachers benefit 
from the current technologies. When the results were examined in terms of computer proficiency scores according to the gender of the teachers, no significant difference was observed. When the computer proficiency scores of teachers were examined by looking at their education levels, a significant difference was found to be between undergraduate and doctorate levels in favor of the teachers with a doctorate degree. Further, by looking at their computer proficiency scores and professional seniority of teachers, it is seen that there is no statistically significant difference. There is no statistically significant difference between computer adequacy scores of the teachers and the class taught. When the results were examined by looking at the computer proficiency scores and computer availability in the classroom, a significant difference was found between the computer proficiency scores of teachers who had computers in their classes and those who had no computers in their classes, in favor of those who had computers in their classes. Based on the results of the study, suggestions were given to teachers, researchers, local government and ministry of education. Teachers were advised to use technology effectively and use training portals in order to make educational activities more effective and efficient. Teachers, especially classroom teachers, should be supported in how to use computers in their classrooms and they should be provided with the necessary training. Instructional programs should be conducted by using computers. During their pre-service education, teacher candidates should be equipped with the required knowledge about the interactive boards used in schools within the scope of Fatih Project.

\section{Kaynakça / References}

Akgül, F., Küpeli, E. ve Kır, İ. (2015). Sınıf öğretmenlerinin bilgisayar okur-yazarlık düzeylerinin belirlenmesi: Kahramanmaraş İli örneği. Elektronik Sosyal Bilimler Dergisi, 14(55), 207-219.

Akyürek, Ç. ve Şahin, Ç. (2013). İlkokul öğretmenlerinin girişimcilik becerisine ilişkin görüşlerinin değerlendirilmesi. Ekev Akademi Dergisi, 17(57), 51-68.

Alkan, C. (2005). Eğitim teknolojisi. Ankara: Anı Yayıncillk.

Arslan, A. (2006). Bilgisayar destekli eğitim yapmaya ilişkin tutum ölçeği. Yüzüncü Yil Üniversitesi, Ë̆̈itim Fakültesi Dergisi, 2(1), 24-33. 
Aslantaş, T. (2014). Uzaktan eğitim, uzaktan eğitim teknolojileri ve türkiye'de bir uygulama. Gazi Üniversitesi, Fen Bilimleri Enstitüsü, Endüstri Mühendisliği ABD, Ankara. 16 Haziran 2016 tarihinde http://www.tankutaslantas.com/wp-content/uploads/2014/04/Uzaktan-Eğitim-Uzaktan-Eğitim-Teknolojileri-veTürkiyede-bir-Uygulama.pdf adresinden erişildi.

Berkant, H.G. (2013). Öğretmen adaylarının bilgisayara yönelik tutumlarının ve özyeterlik algilarının ve bilgisayar destekli eğitim yapmaya yönelik tutumlarınun bazı değişkenler açısından incelenmesi. TheJournal of Instructional Technologies ETeacher Education 3, 11-22.

Bilgin, İ., Tatar, E. ve Ay, Y. (2012). Sınıf öğretmeni adaylarının teknolojiye karşı tutumların n teknolojik pedagojik alan bilgisi (tpab)' ne katkısının incelenmesi. X. Ulusal Fen ve Matematik Eğitimi Kongresi (27-30 Haziran), Niğde Üniversitesi.

Çelik, F., Kocaman, F. ve Önal, A.S. (2008). Burdur İi Merkez İçe ilköğretim öğretmenlerinin bilgisayar okur-yazarlık seviyeleri. Mehmet Akif Ersoy Üniversitesi, Ĕ̆itim Fakültesi Dergisi, 1, 1-13.

Gümüsşdă̆, H., Cerit, E., Gönülateş, S., Arslanoğlu, C., Bastık, C., Şahin, S. ve Ünlü, C. (2013). Beden Eğitimi öğretmenlerinin bilgisayar kullanım yeterlikleri ve tutumlarının belirlenmesi. Uluslararası Hakemli Beşeri ve Akademik Bilimler Dergisi, 2(4).

Gürbüztürk, O., Demir, O., Karadağ, M. ve Demir, M. (2015). Sınf öğretmenlerinin bilgisayar ve internet kullanımına ilişkin öz-yeterlik algılarının bazı değişkenler açısından incelenmesi. Turkish Studies, International PeriodicalfortheLanguages, Literature and History of Turkishor Turkic,10(11), 787-810.

Gürcan, A. (2005). Bilgisayar özyeterliği algısı ile bilişsel öğrenme stratejileri arasındaki ilişki. EurasianJournal of EducationalResearch (EJER). Sayı 19.

Karakaya, İ. (2009). Bilimsel araştırma yöntemleri. A. Tanriöğen (Ed.). Bilimsel Araştırma Yöntemleri, içinde( s. 59). Ankara: Anı Yayıncilık.

Karasar, N. (2006). Bilimsel araştırma yöntemleri. Ankara: Nobel Yayın Dağıtım.

Özden, M. Y., Çağlltay, K. ve Çağlltay, N. E. (2004). Teknoloji ve eğitim: Ülke deneyimleri ve Türkiye için dersler. Türkiye'de İnternet Kullanımı Sempozyumu, Ankara.

Seferoğlu, S. S. ve Akbiylk, C. (2005). İköğretim öğretmenlerinin bilgisayara yönelik öz-yeterlik algiları üzerine birçalışma. Eğitim Araştırmalar-Eurasian Journal of Educational Research, 19, 89-101.

Teo, T. (2008). Assessing the computer attitudes of students: An Asian perspective. Computers in Human Behavior, 24(4), 1634-1642. 
Tinmaz, H. (2004). An assessment of preservice teachers' technology perception in relation to their subject area. Unpublished Master Thesis. Middle East Technical University, Ankara, Turkey.

Timur, B., Yılmaz, Ş. ve Timur, S. (2013). Öğretmen adaylarının bilgisayar kullanımına yönelik öz-yeterlik inançları. Mersin Üniversitesi, Eğitim Fakültesi Dergisi, 9(1), 165-174.

Williams, H.S. ve Kingham, M. (2003). Infusion of Technology Into The Curriculum. Journal of Instructional Psychology, 30(3),178-184.

Yılmaz, M., Üredi, L. ve Akbaşlı, S. (2014). Sınıf öğretmeni adaylarının bilgisayar yeterlilik düzeylerinin ve eğitimde teknoloji kullanımına yönelik algilarının belirlenmesi. 9. Uluslararası Balkan Eğitim ve Bilim Kongresi, Trakya Üniversitesi, Edirne.

\section{Kaynakça Bilgisi / Citation Information}

Yılmaz, M. ve Üredi, L. (2020). İlkokul öğretmenlerinin eğitimde teknoloji kullanımına ilişkin bilgisayar yeterliliklerinin değerlendirilmesi. OPUS-Uluslararası Toplum Araştırmaları Dergisi, 16(32), 4723-4742. DOI: 10.26466/opus.779338 